\title{
Functional Centrality and Innovation Intensity: Employee-level Analysis of the Telenor Group
}

\author{
Fulvio Castellacci*a, Magnus Gulbrandsen*, Jarle Hildrum ${ }^{+}$, \\ Ieva Martinkenaite ${ }^{+} \&$ Erlend Simensen* \\ * TIK Centre, University of Oslo \\ ${ }^{+}$Telenor Research, Oslo \\ ${ }^{a}$ Corresponding author: TIK Centre, University of Oslo, \\ P.O. box 1108, Blindern, 0317 Oslo, Norway. E-mail: fulvio.castellacci@tik.uio.no
}

Research Policy, final version, 1 June 2018

\begin{abstract}
Recent research on employee-level innovation focuses on scientists' ability to source advanced knowledge and use it to create new ideas and innovation within a firm. The present paper introduces a new dimension to this literature: functional departments. We argue that functional centrality, namely the extent to which a functional department is central in the intra-organizational network, affects employees' innovation intensity. We make use of a rich novel dataset at the employee-level for the Telenor Group, based on a large-scale survey among nearly 16,000 employees in all business units and functions of the company. The empirical results point out that employees' innovation intensity is higher in departments that are centrally positioned in the company's internal network. Task characteristics such as quality orientation, entrepreneurial attitude and result pressure moderate the relationship between centrality and innovation.
\end{abstract}

Key words: Employee-level innovation; innovation search; functional departments; functional centrality

JEL codes: L20; O31; O32 


\section{INTRODUCTION}

In the last years, the innovation literature has increasingly studied firms' employees and their innovative activities. Research on employee-level innovation has investigated two related themes. One is employees' external innovation search. Studies of the so-called "variance hypothesis" have shown that employees are more likely to develop innovations when they are exposed to a variety of diverse sources of external knowledge (Laursen, 2012). Recent empirical papers have provided evidence, in particular, that scientists in large firms have a stronger innovation performance when they are able to exploit advanced external knowledge (Gruber et al., 2013; Criscuolo et al., 2014; Salter et al., 2015; Dahlander et al., 2016; Bogers et al., 2017).

The other theme is the diffusion of advanced knowledge within intra-organizational networks, investigating the idea that employees' position in internal networks matters for innovation. Recent empirical papers have studied large firms, notably in the pharmaceutical and semiconductor industries, and shown that scientists' position in their firm's network and their ability to interact with colleagues in different parts of the organization are important factors fostering innovation performance (Guler and Nerkar, 2012; Carnabuci and Operti, 2013; Grigoriou and Rothaermel, 2014; Tortoriello, 2015; Paruchuri and Awate, 2017). However, one important aspect that has not received sufficient attention in this literature relates to firms' organizational structure, and how this can contribute to explain employees' position in intra-organizational networks and their ability to exploit advanced knowledge available in different units of the firm (Laursen, 2012: 1209-1210). In fact, it is reasonable to posit that employees' ability to exploit advanced knowledge does not only depend on individual characteristics but also on the unit of the company in which employees work. Employees' motivations and opportunities to engage in innovation are arguably affected by the overall objectives, tasks and organizational practices of their organizational units. 
One important aspect of the organizational structure that has until now not received sufficient scholarly attention refers to functional departments. Within a functionally organized company, a department is a unit of employees that share common objectives, perform similar and closely related tasks and activities, and are subject to a similar set of incentives and constraints. Examples of functional departments that are typically found within large companies are R\&D, marketing and sales, information technology (IT), and administrative functions.

Each functional department typically specializes in the provision of some core activities and services to other units of the company and/or external agents such as customers and suppliers. Functional departments within the same company thus differ in terms of their core objectives, and the resources and strategies they employ to achieve these objectives. The main argument we develop in this paper is that functional departments' objectives, strategies and organizational practices affect individual employees' motivation and ability to interact with colleagues in other units of the intra-organizational network, and they therefore influence the extent to which employees are exposed to, and can benefit from, intra-firm knowledge.

This is important because it implies that the way in which knowledge flows across functional departments may affect the pace of internal knowledge sharing and innovation performance. Furthermore, this question is not only relevant for scientists that work in companies' R\&D labs, but for all employees that contribute in different ways to generate and diffuse knowledge within a large company. It is well-known that for companies in some industries, and notably in technologically-advanced service sectors, formal R\&D is not the main input into innovations, and employees from other departments of a firm actively contribute to the creation and diffusion of new ideas and innovation. In short, it is paramount to extend employee-level innovation studies by considering individuals working in different 
departments (in addition to R\&D), and investigating how functional departments' characteristics affect employees' innovation activities.

To investigate this unexplored dimension, we introduce the concept of functional centrality, which indicates the extent to which a given functional department is central within the intraorganizational network. By central we mean that the department provides (and/or receives) a core set of activities and services to (and/or from) other functional departments of the same firm. In other words, in a department that is central in a large multi-unit firm, employees typically carry out tasks that are interdependent with those carried out in other functional departments of the company (Thomson, 1967; Puranam et al., 2012; Benito et al., 2014). The key point of our argument is that when a functional department is central its employees will interact on a regular and frequent basis with colleagues of other departments, and they will thus be more exposed to knowledge that is available in the intra-organizational network. This will increase the scope for knowledge sourcing and, due to learning effects, will also strengthen employees' capability to recognize and use advanced knowledge for creating new ideas and innovation. However, in line with previous studies (Salter et al., 2015; Dahlander et al., 2016), we also point out that knowledge sourcing presents opportunity costs such that, beyond a given centrality threshold, the costs of cross-functional knowledge sourcing will outweigh the benefits. Finally, we also put forward the hypothesis that the relationship between functional centrality and employees' innovation is moderated by the nature of tasks that characterize different departments - such as orientation to quality and analytical details (that may strengthen the benefits of centrality), and result orientation and time pressure (that may instead increase the costs of cross-functional interactions).

We investigate these hypotheses using data from the Telenor Group, a multinational telecommunications company headquartered in Norway. Its Organization Culture Survey is a new dataset that comprises information on nearly 16,000 employees from all functional 
departments and business units (subsidiaries) of the firm. Our econometric estimations of a hierarchical ordered probit model of the survey dataset support the idea that functional centrality is important to explain employee-level innovation, and that this positive effect is moderated by departments' task characteristics. Regarding the costs related to crossfunctional collaborations, we find these to be more important for interactions among departments affiliated to different business units (subsidiaries) of the Telenor Group. Our contribution to the literature on employee-level innovation is twofold. First, by pointing out the role of functional centrality for innovation, we add a new conceptual dimension that contributes to explaining why employees within the same firm have different innovation intensities. This has potentially relevant managerial implications, because it suggests that organizational structure and practices in large multi-unit firms can be designed in such a way to strengthen the benefits of cross-functional collaborations and, correspondingly, lower its costs.

Second, as noted above, our paper does not only focus on R\&D personnel and scientists, as most previous research on this topic has done, but it opens up the study of employee-level innovation by also considering innovative efforts carried out by employees in all departments of the firm, which admittedly represent a valuable source of new ideas in technologyintensive service firms. Relatedly, while previous research on scientists' inventive activities has almost exclusively made use of patent data, the present paper makes use of a new rich survey dataset that provides a variety of information and indicators that are better suited to measure innovation activities within a telecommunication company (for which the use of patent data would not be appropriate). 


\section{LITERATURE}

We can distinguish two related strands of research on employee-level innovation. Table 1 presents an overview of the key recent papers in these two strands of research, representing the core literature to which the present study seeks to contribute. The first strand of literature is on external innovation search (Laursen, 2012; Maggitti et al., 2013). This research studies the relationship between scientists' ability to access external knowledge and their innovation output and performance. A central idea is the so-called "variance hypothesis" (Laursen and Salter, 2006): the more diverse sources of external knowledge employees are exposed to, the more likely it is that they will engage in innovation. Exposure to diverse sources of information provides the "requisite variety" of ideas and knowledge needed to create innovations (Dahlander et al., 2016: 280). Openness to external sources of knowledge is therefore a key factor in the creation of new ideas among $R \& D$ scientists and engineers. Seminal papers that developed this idea initially focused on the firm level. Specifically, Laursen and Salter (2006) studied a large sample of UK manufacturing firms, and pointed out that external search breadth and depth affect product innovation performance. Jansen et al. (2005) focused on organizational units within a large MNE and found that organizational antecedents (and particularly those that strengthen internal connectedness among the employees) affect the units' ability to acquire and exploit external knowledge. Foss et al. (2011) studied a sample of 169 large firms and showed that organizational practices that support knowledge sharing and internal communication affect firms' innovation performance. Recent research shifted the focus from the firm- to the employee-level. Table 1 highlights five recent relevant papers in this strand of research. Gruber et al. (2013) analyzed a dataset of 1880 scientists, investigating the idea that inventors' educational background affects their technological recombination breadth. The work found that inventors with a scientific background are more likely to develop broad forms of innovations than those with an 
engineering background. Criscuolo et al. (2014) observed that scientists within a MNE often innovate by using bootlegging, i.e. informal $\mathrm{R} \& \mathrm{D}$ and underground exploration activities to develop new ideas that are not formally accepted by the firm's management. These underground activities are important to sustain innovation performance, particularly in the early phase of ideas' exploration and emergence. Focusing on the same MNE case, Salter et al. (2015) pointed out a curvilinear relationship between external knowledge sourcing and ideation performance (i.e. ability to put external knowledge into use). Dahlander et al. (2016) investigated the trade-off between external search breadth and opportunity costs of sourcing knowledge. The main finding of this work is that scientists differ in terms of the direction and scope of their search activities. Search patterns can be "cosmopolitan" or "local", and the latter denotes an equally successful innovation performance primarily based on interaction with other employees in the same firm. Finally, Bogers et al. (2017) analyzed an employeelevel dataset of 480 firms and found that scientists' educational diversity affects their ability to source external knowledge.

Taken together, these studies advance our knowledge about scientists' ability to absorb and use external knowledge, and on individual and firms' characteristics that affect the ability to source external knowledge. However, this strand of research does not pay sufficient attention to an important complementary source of knowledge, i.e. the one that scientists and R\&D employees can acquire within intra-organizational networks. This is particularly important in large multi-unit companies.

A second strand of research that is relevant for our paper focuses precisely on this aspect, and it studies the relationship between intra-organizational networks and innovation. A central focus in this research is on knowledge exchange within intra-organizational networks, and how inventors' position within the company affects firm-level outcomes. Seminal papers on this topic put forward the idea that the centrality of an organizational unit within a large 
multi-unit corporation is a key factor to foster its innovation performance. Tsai and Ghoshal (1998) and Tsai (2001) focused on business units (affiliates) within MNEs, and pointed out that intra-organizational centrality, in terms of resource exchange and knowledge exchange, respectively, affect business units' product innovation performance. Argyres and Silverman (2004) studied R\&D units within large companies, and investigated the relationship between R\&D organizational structure and the impact and breadth of firms' innovation. More recently, empirical papers on this topic have made increasing use of employee-level data. The lower part of table 1 summarizes five recent empirical papers that are particularly important for our study. Guler and Nerkar (2012) studied collaboration networks of R\&D and scientists' co-patenting in the pharmaceutical industry, and pointed out the aggregate (firmlevel) innovation outcomes of alternative intra-organizational network structures (global vs local cohesion). Carnabuci and Operti (2013) presented an empirical study of how intraorganizational network structure and informal collaborations among R\&D and scientists ("collaborative integration") in semiconductor firms affect firms' recombinant capabilities and patenting performance. Grigoriou and Rothaermel (2014) studied scientists and inventors within pharmaceutical firms, and pointed out the important role of relational stars, inventors that are highly productive and centrally located within a firm's patenting network. Similarly, Paruchuri and Awate (2017) found that inventors' position in the intra-organizational network, and particularly their ability to reach and span of structural holes, affects innovation outcomes. Finally, Tortoriello (2015) focused on the role of brokers, namely "individuals whose network relationships bridge across gaps or 'holes' in the organizational social structure" (p. 588), and showed that inventors' that span structural holes in the intraorganization network are better able to exploit knowledge and thereby innovate. This empirical research sheds new light on the importance of intra-organizational knowledge diffusion, and scientists' position in intra-firm networks. However, a major question that has 
not been systematically examined in this literature refers to the role of the organizational structure for employees' innovation. A few previous studies have investigated this aspect (Argyres and Silverman, 2004; Jansen et al., 2005; Foss et al., 2011) but, as noted by Laursen (2012: 1209-1210), this theme has until now received limited attention.

\section{< TABLE 1 HERE >}

\subsection{Intra-organizational networks and functional centrality}

It is reasonable to argue that the degree to which an employee is central in the intraorganizational network will largely depend on her/his affiliation in the company, and specifically the functional department (FD) to which the employee is affiliated. We thus point to FDs as a relevant and still unexplored conceptual dimension in the literature on employeelevel innovation.

A FD may be defined as a formal unit of employees that share a specific objective within the company, that perform similar and closely related tasks and activities, and that have analogous relationships to other units of the same firm. This definition implies full-time and stable commitment of the FD's employees to a common objective and a set of related tasks. The specific point of our interest is that employees working in the same FD share common objectives, tasks characteristics, and a similar set of incentives and rewards. These functionspecific characteristics affect employees' decisions about how to allocate time across different activities and what tasks to prioritize. Hence, the extent to which they will interact with employees in other FDs of the same company - and thus exploit advanced knowledge available in the intra-organizational network - will to a large extent depend on the overall objectives and characteristics of the FD in which they work. 
Therefore, we argue that centrality can be regarded as a FD-level construct. We define functional centrality as the extent to which a given functional department is central within the intra-firm network. Specifically, a FD may be central either if it systematically provides a core set of inputs, resources and services that are essential to the work done by several other FDs of the company, or if it is systematically recipient of inputs, resources and services provided by other FDs. In both cases, high functional centrality means that the employees working in a given FD will have to interact on a regular basis with colleagues in other FDs of the same company, and will for this reason be more exposed to knowledge available in the intra-organizational network.

To illustrate our point with a simple example, employees in an R\&D Department will typically have frequent regular interactions with colleagues in the marketing and sales department, because the latter can provide important insights and ideas on what new products and services would be suitable to develop and commercialize to the firm's customers. Indeed, to be able to meet the function-specific objective of developing new products that are relevant to customers, the R\&D employees would actively interact with colleagues in the marketing department who have intimate knowledge about customer preferences. Hence, such crossfunctional interactions would not be explained only by R\&D employees' individual attitudes and capabilities, but also by the objective and strategy of the R\&D functional department, and its close organizational ties to the marketing and sales department.

Our concept of functional centrality has two important antecedents. The first is the concept of centrality of a sub-unit of a firm. As noted above, Tsai and Ghoshal (1998) studied the centrality of a business unit (affiliate of a MNE) in terms of "resource exchange and combination" (p.468). Tsai (2001) put forward a similar idea, and postulated that "the higher a unit's in-degree centrality, the more knowledge sources the unit has" (Tsai, 2001: 1000). This is quite similar to the idea presented in this paper, although an important difference is 
that Tsai and Ghoshal's concept focused on the business unit level rather than the FD as we do in this paper.

A second antecedent is related to the concept of interdependence (Thompson, 1967; Puranam et al., 2012; Benito et al., 2014). In general terms, this can be defined as the extent to which the tasks and outcomes of an agent are affected by the tasks and outcomes of another agent (i.e. individual or unit in the same organization). In a large multi-unit company, tasks carried out by different FDs are typically interdependent, since each department is specialized in the provision of a core set of products or services that is used as inputs by the other functions. Thompson (1967) pointed out three distinct forms of interdependencies, which we note here with specific reference to the case of interdependence between functional departments. Pooled interdependence is when tasks are independent, but the total delivery and value depends on both of the tasks performed. Sequential interdependence is when a function cannot perform a task before another function provides it with an input (e.g. like in the case of supplier-producer relationships within the firm). Finally, reciprocal interdependence arises when function A's activities are inputs to function B, and vice versa. The crucial point is that task interdependence among FDs implies frequent regular interactions, and therefore intense knowledge exchange, between different functions. Hence, using Thomson's ideas to illustrate further our concept of functional centrality, we may say that a FD is central within the intraorganizational network if it is interdependent with many other functions.

Further, it is also important to observe that within a MNE, the cross-functional interactions that it is relevant to consider are of two types: (1) within the same BU; (2) across different BUs. The former entails local interactions with colleagues of other FDs that are co-located (Song et al., 1997; Cuijpers et al., 2011); whereas the latter require distance communication and interactions between colleagues that are located in different countries, hence implying cultural communication distance, as well as physical distance and travel costs (Kogut and 
Zander, 1993; Asmussen et al., 2013; Reilly and Scott, 2014). This means that the latter type of centrality may admittedly be subject to higher costs associated with innovation search than the former type.

\section{HYPOTHESES}

Drawing insights from this literature, we put forward a hierarchical model of organizational innovation. Figure 1 depicts our theoretical framework. The model is hierarchical as it points out that innovation in a multi-unit company depends on factors that refer to three related levels of analysis: (1) the employee level, since individual employees' characteristics represent a prime determinant of innovative efforts; (2) the meso-level of functional departments (FD), which is the main focus of this paper; (3) the aggregate business unit (BU) level, since affiliates of a multinational group are characterized by different resources and strategies and face distinct market conditions, national regulations and working cultures.

\section{< FIGURE 1 HERE >}

\subsection{Functional centrality and innovation}

Our theoretical framework focuses in particular on the role of functional centrality for employees' innovative activities. Our main hypothesis postulates a positive relationship between FDs' centrality and employee-level innovation intensity. We argue that if a functional department constitutes an important internal provider or recipient of knowledge, artefacts and services, it will be perceived as an attractive collaboration partner for other departments, and its employees will on average interact more frequently with colleagues of

other departments. As a consequence, its employees will be exposed to advanced knowledge flows arising from intense and frequent interactions with colleagues from several different 
units of the firm. This provides a context which is conducive to diverse search, knowledge recombination and innovation. In central FDs, employees are thus liable to maintain higher innovation intensity than in more peripheral FDs. More specifically, two arguments support this proposition.

First, employees working in central FDs will have access to a greater pool of intraorganizational knowledge, which can be used for the generation of new ideas and innovative activities. This argument is line with Tsai's point (2001: 997) stating that "by occupying $a$ central position in the interunit network, a unit is likely to access desired strategic resources. Such resources will fuel the unit's innovative activities by providing the external information necessary to generate new ideas". Previous research has shown in particular that the breadth of search is important to foster the creation of new ideas and innovation (Laursen and Salter, 2006; Dahlander et al., 2015), and that employees that have a network that spans different parts of the organization will have greater access to a variety of different knowledge assets, and hence have better opportunities for creative knowledge recombination (Tortoriello, 2015). Furthermore, agents working in units that have a central position within a firm internal network will be more likely to be perceived as more trustworthy, and high social capital will foster knowledge sharing and learning (Tsai and Ghoshal, 1998: 466).

A second argument is related to dynamic learning effects and employees' ability to use this pool of advanced knowledge available in the intra-organizational network. In central FDs, frequent interactions with employees of other functional departments will raise employees' awareness of the importance to invest time to generate new ideas, and hence their motivation to develop innovations. In other words, employees will be more aware of the importance of innovation and its benefits, and will therefore make a greater effort to maintain higher innovation intensity than workers in more peripheral FDs. Further, employees in organizationally central FDs are also more likely to develop a greater ability to understand 
and process this pool of advanced knowledge, since they are more systematically exposed to it. In summary, employees working in central FDs will have both greater scope and greater ability to access, exploit and use knowledge available in the intra-organizational network. The key point here is that both of these effects are related to the centrality of the FD in which employees work, which largely determine the extent to which employees can or must interact with colleagues in other FDs to perform their daily tasks.

However, it is also reasonable to posit that in FDs that have a very high degree of centrality, the amount of time that employees will be able to devote to innovation may possibly reach a saturation point. In fact, since activities related to external collaborations, knowledge sharing and network management demand substantial time, these activities may, beyond a certain threshold, turn out to reduce the time that employees have available for innovative activities. The reason for this is that the acquisition and processing of knowledge have an "opportunity cost" (Laursen and Salter, 2006; Dahlander et al., 2016).

First, these costs may be due to the fact that knowledge exchange and interactions with colleagues of other units is an activity that requires sustained time and effort. According to "attention-based theory" (Ocasio, 1997), individuals have limited capabilities to focus and execute tasks, so that spreading attention to a variety of different interaction tasks and knowledge sources can turn out to hamper learning and innovative activities. Second, the acquisition and processing of knowledge also entail coordination efforts, i.e. related to the need to coordinate and integrate different sources of knowledge and apply them in a different context within a given organizational unit (Salter et al., 2015). Thus, while variety of knowledge sources is important for innovation, excessive variety entails high coordination costs that may hamper the generation of new ideas and limit the time available for innovative activities. For these reasons, we postulate that network activities and knowledge sourcing within the firm may, beyond a certain threshold, turn out to reduce the time that employees 
have available for innovative activities and creative thinking. This will be more often the case in FDs that have a very high degree of centrality, in which the "the costs of developing external networks may outweigh the benefits" (Dahlander et al., 2016: 284). Here again, our main point is that these costs are influenced by the degree of centrality of a functional department, that defines the extent to which employees are expected to interact with colleagues in other departments in order to fulfill their tasks. Hence, a function that has higher interdependence will also imply that its employees will face higher opportunity costs related to innovation search and knowledge sourcing. Taken together, these arguments point to the existence of a curvilinear (inverted U-shaped) relationship between FD's centrality and innovation intensity. According to Haans et al. (2016: 1179-1180), the formulation of non-linear relationships should to the extent possible point out the specific theoretical mechanisms that generate the hypothesized curvilinear pattern. In our study, two distinct (though related) mechanisms can generate an inverted Ushaped between functional centrality and employees' innovation. One is based on additive cost/benefit arguments: the time that each employee invests in innovation is determined by a comparison of expected benefits and costs from this activity. The expected benefits increase with centrality (as explained in relation to the first hypothesis), and the costs increase exponentially with rising levels of centrality. The additive combination of expected costs and benefits generates a curvilinear relationship between centrality and innovation.

Relatedly, a different theoretical foundation for this inverted U-shaped curve may be to postulate a multiplicative interaction of two latent linear functions. Specifically, the time that each employee invests in in innovation is determined by the interaction of two factors: (1) the total working time available for innovative activities (which linearly decreases with FD's centrality); (2) the motivation to collaborate and source external knowledge, which is related to the employee's awareness of the importance of these activities (which can be assumed to 
be linearly increasing with FD's centrality). This interaction effect generates highest innovation intensity at intermediate levels of centrality, which combine sufficient available time and high enough individual motivation. Both of the theoretical foundations lead to the following hypothesis:

Hypothesis 1: There is an inverted U-shaped relationship between FDs' centrality and employees' innovation intensity.

\subsection{The moderating role of task characteristics}

Next, we seek to investigate the moderating role of task characteristics. These (sometimes called task orientation in previous organizational research) define the objectives and nature of the working tasks carried out by employees in a given FD, and how these tasks are organized within that organizational unit (West, 1990; Hüsleger et al., 2009). Task characteristics have previously been pointed out as an important dimension in organizational research on the team-level predictors of innovation (West and Anderson, 1996). This literature provided important insights on how individuals organize their innovative activities when working in teams. Further, as noted in section 2, task characteristics do not only represent a factor explaining innovation, but they are also important to define task interdependence among organizational units, namely the extent to which activities carried out in one unit of a company depend upon tasks carried out in another unit (Puranam et al., 2012: 221). Based on this previous research, we posit that task characteristics differ substantially among FDs, and that task characteristics that are predominant in a given FD will affect its employees' motivation, ability and available time to engage with advanced intraorganizational knowledge to develop innovations. Hence, we advance the argument that task characteristics moderate the relationship between functional centrality and employees' 
innovation. Our proposition focuses on three major characteristics of working tasks: quality and analytical detail, entrepreneurial and risk-taking attitude, and result orientation.

First, a key factor pointed out in previous research is quality orientation, which refers to the importance of quality, detail and analytical focus in everyday working tasks, and " $a$ shared concern with excellence of quality of task performance in relation to shared vision or outcomes" (West, 1990: 313). Quality focus and analytical tasks require that employees devote a considerable amount of time to find creative and innovative solutions to fulfill their FD's demand and manage their work in a good manner - such as for instance in a R\&D department, in which the quality and originality of deliverables typically matter more than production costs and delivery times. We postulate therefore that in FDs in which working tasks are highly oriented towards quality and analytical focus, employees will have a greater awareness of the importance of investing some of their working time to generate new ideas, higher expected benefits from innovative activities, and arguably also greater capability to source advanced intra-organizational knowledge to generate innovations. For these reasons, we posit that in FDs characterized by high quality orientation, the relationship between centrality and innovation intensity will be stronger compared to other FDs in which quality and analytical detail are less central characteristics of working tasks.

Hypothesis 2a: The relationship between FDs' centrality and employees' innovation intensity is positively moderated by $\mathrm{FDs}$ 'focus on quality and analytical detail.

Second, another important factor defining working tasks is the entrepreneurial and risktaking orientation, namely the extent to which employees are allowed and/or willing to take new initiatives, and experiment with new solutions that may possibly lead to new or improved products and services, or new or improved ways to execute existing tasks (West, 
1990; Hüsleger et al., 2009). This characteristic of working tasks is also an FD-level construct, since it is predominantly defined by the organizational culture and leadership style that characterize different functions, and that determine the extent to which employees are encouraged to be creative or if they have to avoid unnecessary risks and focus on routine tasks and fulfillment of performance criteria. Our specific proposition is that this characteristic of working tasks also positively moderates the relationship between functional centrality and innovation. Specifically, in FDs in which employees are allowed to take initiatives, experiment and try out new solutions, individual workers may arguably have greater awareness of the benefits associated with intra-organizational interactions, higher openness and willingness to learn from colleagues in other organizational units, as well as more available time to apply advanced knowledge to develop new ideas and innovation. By contrast, in FDs in which employees are not allowed, or not encouraged, to take new initiatives and think 'out of the box', it will be less likely that knowledge available in other units of the intra-organizational network will be actively used for innovative activities, and employees will therefore invest less of their working time in innovative activities.

H2b: The relationship between FDs' centrality and employees' innovation intensity is positively moderated by FDs' entrepreneurial and risk-taking attitude.

Third, another task characteristic that is important for our study is result orientation. This may be defined as the extent to which employees' work is subject to external pressure - from the market and/or from their corporation's management - to deliver results and achieve high performance in a timely manner. Result orientation is also an FD-level conceptual dimension, since it is largely determined by the objectives of the functional department in which employees work, and the time that is available to carry out working activities and achieve 
these objectives (West, 2002). We hypothesize that result orientation negatively moderates the effects of functional centrality on innovation. It is in fact reasonable to think that in FDs where there is a strong pressure to deliver results and fulfill performance criteria in a timely manner, production, execution and delivery times will be crucial, whereas the time that employees can devote to creative work and exploration of new ideas will be reduced. Hence, although high functional centrality provides opportunities to get access to advanced intraorganizational knowledge, these opportunities will not be reaped if employees' work is subject to strong result pressure within their functional department. Strong result orientation may hamper individuals' motivation to engage in interactions with colleagues in other departments, and hence the benefits of these in terms of generation of new ideas and innovation.

H2c: The relationship between FDs' centrality and employees' innovation intensity is negatively moderated by $\mathrm{FDs}$ ' pressure to deliver results.

\section{DATA AND METHODS}

\subsection{Survey data and design}

Telenor is one of the world's 15 largest mobile telecommunications operators with 176 million mobile subscriptions and a workforce of 36,000. The headquarters are in Norway, and the company has 12 BUs (affiliates) in the Nordic Region, Central and Eastern Europe, and Asia. Telenor has evolved into a multi-domestic organization characterized by a hierarchical and functionally organized structure. Telenor has in recent years developed a strategy for better integration of its business units. In order to map knowledge flows, the company undertook the large-scale Telenor Organization Culture Survey in 2014. This resulted in a 
new dataset providing information on almost 16,000 employees across 14 BUs worldwide. The same survey was repeated in 2016 with 20500 unique respondents. A total of 9177 employees responded to both the 2014 and 2016 survey. This dataset represents a unique employee-level empirical source to investigate innovation activities within a large corporation, and their relations to a variety of individual and organizational factors. Tables $2 \mathrm{a}$ and $2 \mathrm{~b}$ report the response rate. The Appendix provides further information on the methodology used to carry out the survey, as well as a description of the quality and robustness of the survey in terms of non-response bias and common method bias. The results presented in this paper are based on an econometric analysis of this survey dataset. However, to get a more thorough understanding of some of the survey questions and the underlying patterns, we also carried out a number of interviews with top and middle-level managers representing different FDs of the company.

\section{< TABLES 2a AND 2b HERE >}

\subsection{Variables and empirical model}

\section{DEPENDENT VARIABLE.}

INNO: innovation intensity. Survey question: "How much of your time do you spend working with innovation?" Responses used a categorical scale ranging from 1 (min) to 5 (max). We use this as a measure of employees' innovation intensity, the dependent variable in our empirical analysis. The variable INNO is measured in the 2016 survey (i.e. the second wave of the Telenor Organization Culture Survey), whereas all other explanatory variables in the model are measured on the survey results for the year 2014 (first wave of the survey). The 
two-year lag between dependent and explanatory variables alleviates possible econometric issues related to simultaneity and/or endogeneity of some of the regressors. ${ }^{1}$

Figure 2 shows the overall distribution of the innovation intensity variable in our dataset, and tables $3 \mathrm{a}$ and $3 \mathrm{~b}$ present its distribution by FDs and BUs respectively. We also compared our self-reported innovation intensity variable with the official R\&D intensity figures aggregated at the BU-level. This comparison shows a positive and significant correlation between the two variables, which suggests that the indicator we use in this paper represents a reliable proxy of innovation intensity.

To get a further understanding of this variable, we asked during the interviews what Telenor's employees mean by innovation in their daily work. The interviews point to three general patterns that hold for Telenor employees in all FDs. First, employees have a broad understanding of what innovation is, and different types of innovation are emphasized by workers in different functions (e.g. process, product, service, organizational changes). Second, the word 'innovation' is in most FDs coupled with an increasing focus on users ('Innovation is about doing something better for the customer"; employee in Telenor Norway). Third, most think that innovation in the company largely refers to incremental changes rather than radical innovation, which is in line with the description of team-based innovation put forward by Anderson and West (1998: 239). On the whole, these insights point out that what our empirical analysis focuses on is a set of FD-level factors that explain user-oriented and incremental innovation, and that the specific type of innovation activity done by the employees varies among the different FDs.

\section{< FIGURE 2, TABLE 3a AND TABLE 3b HERE >}

\footnotetext{
${ }^{1}$ The fact that the dependent variable is only available in the 2016 survey means that we are not able to consider changes in the dependent variable between the two surveys. This excludes the possibility to analyze our hypotheses using panel data methods and/or diff-in-diff (before/after) comparisons.
} 
The explanatory variables include the factors highlighted by our hypotheses and control variables. The explanatory variables testing the hypotheses are all measured at the FD-level, whereas the control variables refer to both FD-level and employee-specific characteristics. Table 4 presents descriptive statistics for these indicators.

\section{MAIN EXPLANATORY VARIABLES.}

As noted in section 3, functional centrality refers to two aspects: centrality with respect to cross-functional interactions that employees have within the BU (affiliate) in which they work, and cross-functional interactions with employees working in different BUs (i.e. located in different countries). We measure these two aspects by means of the following variables. CENTRAL_FD: cross-functional interactions within the same BU. Survey question: “How often do you share knowledge with employees within your BU about the following activities: customer groups and markets; new service development; new ways to serve the customers; Telecom infrastructure; best practices about marketing, technology or sourcing; developing corporate strategy; solutions and best practices from third-party companies?"

CENTRAL_BU: cross-functional interactions with employees in other BUs. Survey question: "How often do you share knowledge with employees in other BUs about the following activities: customer groups and markets; new service development; new ways to serve the customers; technology and telecom infrastructure; best practices; strategy; solutions and best practices from third-party companies?".

These survey questions were asked to each employee of the company, but the variables CENTRAL_FD and CENTRAL_BU are measured at the FD-level (i.e. we calculated the average response for each FD and in each BU). The underlying idea of these indicators is that FDs in which employees have on average intense interactions and frequent knowledge exchanges with colleagues in other FDs (within and across BUs) can be considered to be 
more central within the company. High centrality and intense external interactions are important precisely because they provide the potential for knowledge exchange, learning and innovation, according to the main hypothesis developed in section 3. Specifically, the reason to average individual-level data at the FD-level is that centrality is here defined as a functionlevel concept, based on the idea that employees' willingness to share knowledge with other colleagues and ability to exploit intra-organizational knowledge depends on the overall objectives and tasks of the FD in which the employee works. ${ }^{2}$

Our indicators are similar to those used by Tsai and Ghoshal (1998: 470), which adopted an indicator of centrality measured in terms of "resource exchange among units". Both our indicator and Tsai and Ghoshal's measure the average frequency of knowledge exchange between an organizational unit and the others. Specifically, Tsai and Ghoshal's (1998) indicator measures the average number of employees that consider a given unit a frequent exchange partner; whereas our indicator measures the average frequency of interactions reported by employees working in a given unit. The main difference is that the former focuses on organizational units in terms of affiliates (i.e. business units of the same MNE), whereas our main interest is to calculate an indicator of centrality of functional departments.

\section{OTHER EXPLANATORY FACTORS (FD-LEVEL).}

First, we use some variables that measure task characteristics (West, 1990; Hüsleger et al., 2009). We make use of four variables that measure three different characteristics of working tasks. In our survey dataset, these variables are defined at the FD-level, i.e. each employee was asked to describe the importance of distinct working tasks for the department in which she works.

\footnotetext{
${ }^{2}$ In the regression analysis, however, we have also carried out some robustness analysis of this point, and run a battery of additional regressions that include the employee-level centrality variables in addition to the corresponding FD-level variables. We will briefly discuss these additional results in section 5 .
} 
ANALYTICAL: Quality and analytical detail in working tasks: "To what degree does 'being analytical' characterize the current culture in your department?"

ENTREPRENEURIAL: Entrepreneurial and risk-taking attitude in working tasks: "To what degree do the following statements ('risk taking', 'being willing to experiment', and 'taking initiative') characterize the current culture in your department?"

RESULT: Result orientation in working tasks: "To what degree do the following statements ('being result-oriented'; 'having high expectations for performance'; 'being achievementoriented'; 'being action oriented') characterize the current culture in your department?" EFFICIENCY: Efficiency orientation in working tasks: "To what degree do the following statements ('conducting the work at the lowest cost possible', 'bringing down costs to a lower level than our competitors', 'reducing the overall level of costs', and 'do the work in a more cost-efficient manner') characterize the current culture in your department?"

Next, we also include a variable measuring the leadership style that characterizes each FD, particularly with respect to the degree of empowerment and autonomy that employees have, and which arguably affects their willingness and possibility to invest time in innovation. As pointed out in research on team performance (Ilgen et al., 2005), an organizational culture that fosters innovation is greatly dependent on the team's leadership (Hambrick and Mason, 1984; Crossland and Hambrick, 2007). Through promotion of a specific vision and shared values, the leadership contributes to shaping employees" "clarity of and commitment to objectives" (West and Anderson, 1996: 682). It may enable internal cohesion, i.e. strong commitment to teamwork and membership (Hüsleger et al., 2009). It can also provide active support for innovation and tolerance of failures, i.e. the "expectation, approval and practical support of attempts to introduce new and improved ways of doing things in the work environment" (West, 1990: 315). Finally, a leadership culture oriented towards innovation tends to foster active participation of team members in decision-making, and by empowering 
workers it creates conditions to foster creativity and innovation (Srivastava et al., 2005; Jansen et al., 2005). We therefore define the variable EMPOWERMENT, based on the following survey question: "To what extent do empowerment of employees and appreciation of independent initiative characterize leadership in your department?" We used a categorical scale from $1(\min )$ to 7 (max). All of the survey questions that we have used to construct the variables defined in this section are based on the Organizational Culture Profile developed by O’Reilly et al. (1991).

\section{CONTROL VARIABLES (EMPLOYEE-LEVEL).}

EDUCATION is the education level of each employee (measured on a 0 to 5 scale).

According to Bogers et al. (2017), this is important to explain employee-level openness and the ability to acquire advanced knowledge. TENURE is an indicator measuring the number of years the employee has worked in a given FD. According to Gruber et al. (2013), this variable is important because longer tenure implies more experience and hence higher absorptive capacity, but it also implies that the employee's education is more distant in time, and this may hamper her innovative capability and learning motivation. DIVERSITY is a variable measuring the degree of tolerance to other employees' diversity in terms of nationality and gender. GENDER is a dummy variable controlling for the employee's gender. Finally the variable ATTITUDE provides a proxy measure of the employee's attitude and personality. This control variable seeks to take into account the fact, common to several survey designs, that some of the respondents have systematically higher (or lower) response values on most of the survey questions than other respondents, due e.g. to individual characteristics (attitude and personality) and/or different cultural values. As a basis for this variable we use the Organizational Culture Profile battery of the Telenor survey (O'Reilly et al., 1991) in which the respondents are asked to indicate both how characteristic a set of 
cultural traits are for their department and how desired the same traits are. Hence, for each of the explanatory variables noted above, we have calculated a "gap" variable - measuring the perceived gap between the "desired" and "actual" characteristic of the department according to the employee - and then computed an average of all of these "gap" indicators. The resulting variable is a proxy measure for individual respondents' attitude, which we use as a control variable in the regressions.

\section{< TABLE 4 HERE >}

The econometric model specification is the following:

$$
\begin{aligned}
& \text { INNO }_{i j z}=\alpha+\beta \text { CENTRAL_FD }_{j z}+\gamma \text { CENTRAL_BU }_{j z}+\eta \text { ANALYTICAL }_{j z}+ \\
& \lambda \text { ENTREPRENEURIAL }_{j z}+\delta \text { RESULT }_{j z}+\varphi \text { EFFICIENCY }_{j z}+\theta \text { EMPOWERMENT }_{j z}+ \\
& \sum_{m}\left[\kappa_{m} \text { CONTROL }_{m}\right]_{i j z}+\omega \mathrm{FD}_{j z}+\psi \mathrm{BU}_{z}+\varepsilon_{i j z}
\end{aligned}
$$

This is a three-level hierarchical model where the subscript $i$ denotes the employee, $j$ indicates the FD in which each employee works, and $z$ denotes the BU to which each employee is affiliated. As noted above, the key relationships of interest refer to the effects of FD-level explanatory variables (those noted with a $j z$ sub-index in equation 1 ) on employeelevel innovation intensity (and specifically the role of centrality and the related moderating effects). The basic reason for specifying a hierarchical model is precisely that, due to the hierarchical nature of the multinational company that we study, it is reasonable to posit that employees belonging to the same department and/or to the same BU will share some common characteristics. Such clustering of observations at different levels of analysis may lead to 
biased standard errors in a non-hierarchical econometric model. A multi-level model like the one specified in equation 1 overcomes this issue.

We will estimate three versions of equation 1 . The first is the baseline specification, where the parameters $\beta$ and $\gamma$ test a baseline linear relationship between functional centrality and innovation intensity. In the second, we add a quadratic term for the variables CENTRAL_FD and CENTRAL_BU, testing for hypothesis 1 . The third version adds interaction effects to test the moderating role of task characteristics, relating to hypotheses $2 \mathrm{a}, 2 \mathrm{~b}$ and $2 \mathrm{c}$. We test interaction effects both in the linear version of the model and on the quadratic terms, as recommended by Haans et al. (2016).

We estimate this model by means of two econometric methods. First, we estimate an ordered probit model, since the dependent variable is an ordered categorical variable. The shortcoming of this first approach is that it does not take into account the hierarchical nature of the data, and it may therefore lead to biased standard errors. Second, we estimate the model as a three-level hierarchical ordered probit model, where the three levels of analysis are the employee-, FD- and BU-level. Specifically, we estimate this multi-level model as a mixed fixed effects and random-slope model, i.e. where fixed effects take into account unobserved characteristics at each level of analysis (employee, FD and BU), whereas the random effects at the FD-level allow the effect of each explanatory variable on innovation to vary across functions.

\section{EMPIRICAL RESULTS}

Tables 5 and 6 present the results of the econometric estimation of Equation 1 (baseline model specification, without quadratic terms and interaction effects). The first five variables reported in table 5 are the employee-level control factors. Among these, it is worthwhile to observe that employees with a higher education level have on average higher innovation 
intensity, whereas higher tenure is not significantly related to the dependent variable. This is arguably due to the fact that employees with longer experience in the company are also those that completed their education several years ago, and this is a factor that may hinder their motivation and propensity to spend time to generate new ideas (Bogers et al., 2017).

The next five variables reported in Table 5 investigate the role of FD-level characteristics, in particular the characteristics of working tasks and how these can affect employees' innovation intensity. The variable ANALYTICAL is positively related to innovation intensity, indicating that employees working in FDs in which quality and analytical detail are important features of working tasks invest on average a greater share of their working time to develop innovations. The coefficient for the variable ENTREPRENEURIAL is also positive and significant, and it has a relatively large magnitude. This confirms that when employees are encouraged to experiment with new ideas and solutions, and this forms an integral part of their FD's organizational culture, they tend to spend more time on innovative activities. The variable RESULT has instead a negative, large and statistically significant coefficient, indicating that in functional departments with strong pressure to deliver results and where production, execution and delivery times are crucial, the amount of time that employees devote to innovation will correspondingly be more limited. Further, the variable EFFICIENCY points out a positive and statistically significant relationship between FD-level cost efficiency orientation and employee-level innovation. This may be due to the fact that in the departments where minimizing production costs is a priority, employees must devote sufficient resources and time for creative thinking and innovation in order to find more efficient ways to manage and organize their working tasks.

Finally, the results show a positive and statistically significant relationship between the variable EMPOWERMENT and the dependent variable INNO. This is in line with the argument in the management literature that a leadership culture that empowers workers and 
enhances their autonomy fosters creativity and innovation (Hambrick and Mason, 1984; West and Anderson, 1996; Crossland and Hambrick, 2007; Srivastava et. al. 2007).

Turning now to the test of the main hypothesis, the two variables that we have used in the regressions to assess the role of FD's centrality for employees' innovation intensity are CENTRAL_FD (cross-functional collaborations within the same BU) and CENTRAL_BU (cross-functional collaborations among different BUs). Table 5 shows that both of these variables are positive and significant in both of the regression models (with the exception of CENTRAL_BU in the last column of table 5). These patterns corroborate the idea that if a functional department has high centrality, its employees will be highly exposed to knowledge flows arising from intense and frequent external collaborations with other colleagues, and they will thus have higher motivation and ability to use intra-organizational knowledge to generate new ideas and develop innovations. The novel aspect of this result, compared to previous studies on the role of organizational centrality (Salter et al., 2015; Tortoriello, 2015), is that we show that the extent to which an employee is exposed to knowledge that fosters innovation is largely defined by the FD in which s/he works. ${ }^{3}$

Table 6 reports the estimated random effects of the hierarchical model. The table reports a random effect for each FD, showing the extent to which the effect of centrality on innovation intensity varies across functions. The estimated random slopes indicate that the two variables measuring FD's organizational centrality have a stronger effect on employees' innovation intensity in two functional departments of Telenor: R\&D and Operations (and to a less extent Support Functions). These are the FDs in which, according to our results, knowledge flows

\footnotetext{
${ }^{3}$ However, to assess the robustness of this finding, we have also run a battery of additional regressions that include the centrality variables measured at the employee-level in addition to the corresponding FD-level centrality variables. These regressions are not reported in the paper to save space, and they are available upon request. The results of these additional exercises are largely in line with those reported in table 5. However, results of hierarchical regressions that simultaneously include both FD- and employee-level centrality variables are not statistically significant. This is arguably due to the fact that these variables are highly multicollinear (by construction), so that including all of them simultaneously in the same hierarchical model results in nonsignificant estimates for the upper-level variable.
} 
related to the functions' centrality lead employees to invest a greater share of their working time to innovation.

\section{< TABLES 5 AND 6 HERE >}

We now shift the focus to the results presented in table 7. Our main hypothesis postulates that the positive relationship between FDs' centrality and employees' innovation intensity is nonlinear (inverted U-shaped). Such quadratic relationship may be explained by the idea that exploiting advanced knowledge may also present some opportunity costs; managing network relationships and applying knowledge to a different context require substantial time and effort. When these costs are too high, it is reasonable for an employee to decide not to invest more time in knowledge sourcing and innovation search, and rather focus on other routine tasks and more urgent deliverables.

Table 7 presents the results of an estimation of a specification of equation 1 that includes these quadratic terms. For the variable CENTRAL_FD, the quadratic term is negative (indicating an inverse U-shaped relationship) but not significant. Further, the turning point of the quadratic relationship lies outside of the range of the centrality variable, implying that it is not economically meaningful to consider this threshold (Haans et al., 2016). On the other hand, the quadratic term for the variable CENTRAL_BU is negative and significant in the ordered probit estimations, but only weakly significant in the hierarchical ordered probit regressions. In both cases, though, the turning point of the quadratic relationship lies within the range of the centrality variable. This indicates that in FDs that have centrality values above (around) 4.5 (i.e. about one point above the mean of this indicator) the costs of interacting with colleagues in other BUs overcome the benefits, so that high functional centrality turns out to decrease employees' innovation intensity. Although this result should 
be interpreted with caution due to weak precision of the results in the hierarchical ordered probit regressions, it is however interesting to observe that the hypothesized inverse Ushaped relationship holds only for the CENTRAL_BU variable (and not for the CENTRAL_FD). Arguably, this is due to high costs that employees may incur when interacting with colleagues that work in BUs located in different countries; in such situations geographical and cultural distance makes it more costly to exploit intra-organizational knowledge and use it to generate new ideas and innovation. On the other hand, interacting with colleagues within the same BU (located in the same country) admittedly presents lower opportunity costs, and this may explain why we do not find support for an inverted U-shaped relationship for the variable CENTRAL_FD.

\section{< TABLE 7 HERE >}

The next and final step is the test of hypotheses $2 a, 2 b$ and $2 c$. These propositions put forward the idea that task characteristics moderate the positive relationships between functional centrality and innovation intensity. To test these hypotheses, we interact the variables CENTRAL_FD and CENTRAL_BU with the variables measuring the three task characteristics, namely ANALYTICAL, ENTREPRENEURIAL and RESULT. In discrete choice econometric models, such as the ordered probit model used here, the relevance and significance of interaction variables has to be evaluated by looking at their marginal effects (Ai and Norton, 2003). Table 8 reports the marginal effects obtained from an estimation of a specification of equation 1 that includes these interaction variables (and without quadratic terms).

The econometric results provide support for all three hypotheses. First, orientation towards quality and analytical detail increases the effect of functional centrality on innovation 
intensity, suggesting that FDs that combine high centrality and high quality focus are those in which employees have highest motivation to invest working time to develop new ideas and innovation (hypothesis 2a). Second, the interaction effect for the variable measuring FDs' entrepreneurial and risk-taking attitude is also positive, in line with our argument that employees are more inclined to invest time in innovation if they work in FDs that combine high centrality and innovative culture that fosters individual initiative and exploration of new ideas generated through cross-functional collaborations (hypothesis $2 b$ ).

Comparing the magnitude of the two interaction variables, it is also interesting to note that the moderation effects of quality and analytical orientation is stronger for knowledge sharing within the same BU than across BUs; the opposite pattern is true for the moderation effect of entrepreneurial and risk-taking attitude. A possible explanation of this finding is that exploitation of knowledge from other BUs requires more intense interaction with colleagues working in different affiliates of the Telenor Group, where geographical and cultural distance presents risks of failure that only FDs that support entrepreneurial and risk taking attitude will support. On the other hand, it may be argued that FDs in which quality and analytical details are important, employees will be less likely to explore knowledge available in other BUs, and rather focus on advanced knowledge that can be obtained by interacting with colleagues in other FDs of the same BU.

Third, the variable interacting centrality and result orientation is as expected negative and significant, meaning that pressure to deliver results negatively moderates the positive relationship between centrality and employees' innovation intensity (hypothesis $2 \mathrm{c}$ ). The argument underlying this hypothesis is that in FDs characterized by a strong pressure to achieve results in a timely manner, employees will be less inclined to spend some of their working time to generate new ideas, and will instead prefer to focus on routine tasks that lead to the fulfillment of their core and more urgent objectives. 
We also carried out an additional empirical exercise, which provide a further test of hypotheses $2 \mathrm{a}, 2 \mathrm{~b}$ and $2 \mathrm{c}$. Specifically, we tested whether the moderating effect of task characteristics has any influence on the quadratic relationship between organizational centrality and innovation intensity (in addition to their effect on the linear version of this relationship that we commented upon above here). Table 9 reports the results of the estimations of an augmented specification of equation 1 that includes quadratic terms as well as interactions between these non-linear terms and the moderating variables (following the guidelines in Haans et al., 2016: 1187-1188). However, we only carried out this additional test for the variable CENTRAL_BU, since as noted above the quadratic term for the variable CENTRAL_FD is not supported by our econometric results (see table 7) and it is therefore not reasonable to consider it further.

The results in table 9 provide mixed and non-conclusive support for the idea that task characteristics affect the position and/or the shape of the inverse U-shaped relationship between centrality and innovation intensity. The estimated coefficients are in fact significant for two of the interaction variables only in the ordered probit regressions, but not in the hierarchical ordered probit model. These results suggest that the variable ANALYTICAL and the variable RESULT shift the inverse U-shaped relationship and its turning point towards the left. This means that a greater focus on quality and analytical details and a greater pressure to achieve results increase the costs associated with intra-organizational interactions and knowledge sharing, hence lowering the threshold at which functional centrality will stop fostering innovation intensity. These patterns are interesting, although they are not supported by the hierarchical version of our model, and they must therefore be interpreted with caution.

\section{< TABLES 8 AND 9 HERE >}




\section{CONCLUSIONS}

The general idea put forward in this paper is that employees in different functions of the same company pursue different objectives and face a different set of incentives and constraints for innovation. These department-level factors, in turn, may affect employees' motivation and ability to interact with colleagues in other units of the same firm, and therefore the extent to which the employees' are able to source advanced knowledge and use it to develop new ideas and innovation. To investigate this idea, we have developed the concept of functional centrality, arguing that the extent to which an employee interacts and shares knowledge with other colleagues in the same company is affected by the centrality of the functional department in which the employee works. Our empirical analysis highlights three main findings.

First, functional centrality is positively related to employees' innovation intensity. Crossfunctional interactions, both within and across geographically defined business units of the Telenor Group, are important to spur employees' innovation efforts. However, crossfunctional collaboration, although generally perceived as important for innovation, is typically affected and often hampered by the distinct set of performance measures and incentive systems adopted by different FDs. In order to strengthen further collaboration across functional departments, specific innovation projects may be organized to have aligned goals, shared ownership and performance measurement across FDs.

Second, we find evidence that the relationship between centrality and innovation is inversely U-shaped, but only with respect to cross-functional collaborations among distinct BUs. We interpret this curvilinear relationship as the result of increasing opportunity costs related to higher levels of centrality, and which may be more substantial when employees interact with colleagues working in other BUs, given that high geographical and cultural distance may 
increase the costs of external knowledge sourcing and collaboration. Although our econometric evidence on this finding is mixed and non-conclusive, this is an important point that managers of innovating organizations should assess further. It could be important to find an appropriate balance between, on the one hand, openness towards new ideas and variety of knowledge sources in the intra-organizational network and, on the other hand, the need to maintain attention and focused efforts on a limited set of collaboration activities that are deemed to be more promising in terms of their innovation potential.

Third, the positive relationship between centrality and innovation is moderated by the type of working tasks that characterize different FDs. Specifically, this relationship is strengthened in functional areas where employees have the possibility to focus on quality and analytical details, and take initiatives to develop new ideas. The reason is that these FDs represent working environments in which employees have greater awareness of the importance of innovation and stronger incentives to invest some of their working time in it. On the other hand, we find that result orientation negatively moderates the centrality-innovation link. Company pressure to achieve results in a timely manner makes it more costly for employees to invest time to develop new ideas whose benefits are uncertain and will only be realized in the future. This implies that managers should aim for the appropriate balance between shortand long-term objectives that workers have to fulfill in their daily work - too strong pressure to achieve results in the short term may hamper the generation of new ideas and innovation that may be important for the company in the longer term.

On the whole, the paper's contribution to the literature on employee-level innovation is twofold. First, thanks to the availability of a rich dataset containing information on thousands of employees working in different parts of the same multinational company, we have shown that knowledge sourcing and innovation are important activities that are carried out by workers in different parts of a company, and not only by scientists and engineers working in 
R\&D. Future studies should extend employee-level innovation research by investigating further innovative activities carried out by a variety of employees within firms, and how these interact with scientists and R\&D personnel to create innovations.

Second, we have developed new arguments and provided evidence that employee-level innovation activities are not only determined by individual characteristics (such as e.g. education level and diversity of expertise), but they are also shaped by the characteristics of the functional department in which employees work. The present paper has focused on one important aspect - centrality - but it is important that future research will extend this new line of research by investigating a variety of other functional characteristics and organizational practices that may shape employees' innovation.

\section{APPENDIX: TELENOR ORGANIZATION CULTURE SURVEY}

In a pilot phase of the survey data collection, a team consisting of researchers from the University of Oslo and Telenor's internal R\&D department conducted 40 semi-structured interviews to better understand contextual differences in the corporation, and to develop survey instruments. In March 2014, the questionnaire was sent to all 24571 full-time employees of Telenor (except for Bulgaria and Myanmar business units), effectively making it a census of the group. After three weeks, 15793 respondents had returned the questionnaire. The survey achieved a response rate of above $50 \%$ in most BUs with a peak of $77 \%$ in Malaysia and a low point of $36 \%$ in the central unit Broadcast. Overall, the response rates in the 2014 and 2016 surveys were $63 \%$ and $65 \%$, respectively.

To assess non-response bias, we analyzed differences in respondent versus non-respondents with respect to two employees' characteristics: gender and tenure (we only focused on these variables as we did not have information on other employee-specific characteristics for the 
group of non-respondents). We carried out Chi-square tests to analyze the differences between the two groups in the 2014 survey (which is the one that we use to measure our explanatory variables in the regressions). Our results show that the gender of respondents and non-respondents was not statistically significantly different from each other ( $\mathrm{p}$-value $=0.367$ ). On the other hand, we found statistically significant differences between respondents and non-respondents with respect to tenure. However, this difference is mostly driven by employees with short tenure (i.e. recently employed who have been at Telenor for less than one year), and which represent a relatively small number of observations in our sample. For all other employees in the company (tenure $>1$ year), which account for the bulk of our sample, shares of respondents and non-respondents are very close to each other. Hence, nonresponse bias does not seem to be a major concern for this survey dataset.

Regarding common method bias (CMB), during the preparation of the survey instrument we took several measures to avoid this issue. Firstly, the data forming the basis of all predictor variables in our study were collected through a survey carried out in 2014 while the data on the criterion variable was collected through a subsequent survey carried out in 2016. According to Podsakoff et al. (2003: 898), when the predictor and criterion variables are taken from two different sources, the issue with common method bias is less critical. Secondly, to make it less likely for respondents to speed through the survey without carefully considering each question, we used several different types of item scales (5-step and 7-step Likert) as well as two reverse coded items. Thirdly, as noted in section 4.2, we also included an average gap variable measuring the difference between perceived and "desirable" organizational characteristics (see variable ATTITUDE). This variable controls for differences between respondents that have systematically positive and systematic negative attitudes (thus alleviating the possible negative effects of $\mathrm{CMB}$ ). 
Fourthly, to test more formally whether common method bias (CMB) is a problem in our study, we conducted a Harman's single factor score test (Podsakoff et al. 2003). We loaded all survey items measuring the constructs in our paper into one single factor. The total variance for the first factor was $36 \%$, which is below $50 \%$, suggesting that common methods bias is not a serious concern for our analysis (Podsakoff et al. 2003, 2012). Indeed, this procedure identified seven factors and the variance did not derive from the first factor only. Taken together, these methodological precautions and further tests indicate that CMB is not a problem for our empirical analysis.

\section{ACKNOWLEDGMENTS}

A previous draft of this paper was presented at the EMAEE Conference in Strasbourg in May 2017, a seminar at BI in Oslo in August 2017, and a seminar at Telenor in Oslo in November 2017. We wish to thank the discussants at these events, as well as the Editor and two anonymous reviewers of this journal for the very helpful comments and suggestions. We also acknowledge Vegard Tveito for his research assistance work during the first phase of this project. 


\section{REFERENCES}

Ai, C. and Norton, E. (2003). 'Interaction terms in logit and probit models'. Economics Letters, 80, 123-129.

Anderson, N., \& West, M. (1998). 'Measuring Climate for Work Group Innovation: Development and Validation of the Team Climate Inventory'. Journal of Organizational Behavior, 19, 235-58.

Argyres, N.S. and Silverman B.S. (2004). 'R\&D, Organization Structure, and the Development of Corporate Technological Knowledge'. Strategic Management Journal, 25, $929-958$.

Asmussen, C., Foss, N.J., \& Pedersen, T. (2013). 'Knowledge Transfer and Accommodation Effects in Multinational Corporations Evidence from European Subsidiaries'. Journal of Management, 39, 1397-429.

Benito, G., Lunnan, R. and Tomassen, S. (2014). 'The virtue of in-between pragmatism-a balancing act between responsiveness and integration in a multinational company'. Advances in International Management 27, 75-97.

Carnabuci G, Operti E. (2013). 'Where Do Firms' Recombinant Capabilities Come From? Intra-Organizational Networks, Knowledge, and Firms' Ability to Innovate through Technological Recombination'. Strategic Management Journal 34, 1591-1613.

Criscuolo P, Salter A, Wal ALJT. (2014). 'Going Underground: Bootlegging and Individual Innovative Performance'. Organization Science 25, 1287-1305.

Bogers, M., Foss, N. and Lyngsie, J. (2017). 'The "human side" of open innovation: the role of employee diversity in firm-level openness'. Research Policy, in press.

Crossland, C. and Hambrick, D. C. (2007). 'How national systems differ in their constraints on corporate executives: a study of CEO effects in three countries'. Strategic Management Journal 28, 767-89. 
Cuijpers, M., Guenter, H. \& Hussinger, K. (2011). 'Costs and Benefits of Inter-Departmental Innovation Collaboration'. Research Policy 40, 565-75.

Dahlander L., O'Mahony S. and Gann D.M. (2016). 'One Foot in, One Foot Out: How Does Individuals' External Search Breadth Affect Innovation Outcomes?' Strategic Management Journal, 37, 280-302.

Foss, N.J., Laursen, K. and Pedersen, T. (2011). 'Linking Customer Interaction and Innovation: The Mediating Role of New Organizational Practices'. Organization Science, 22, 980-999.

Grigoriou, K. \& Rothaermel, F. (2014). 'Structural microfoundations of innovation: The role of relational stars'. Journal of Management, 40, 568-615.

Gruber, M., Harhoff, D., and Hoisl, K. (2013). 'Knowledge Recombination across Technological Boundaries: Scientists Vs. Engineers'. Management Science, 59, 837-851.

Guler I, Nerkar A. (2012). 'The Impact of Global and Local Cohesion on Innovation in the Pharmaceutical Industry'. Strategic Management Journal 33, 535-549.

Haans, R., Pieters, C. and He Z-L. (2016). 'Thinking About U: Theorizing and Testing Uand Inverted U-Shaped Relationships in Strategy Research'. Strategic Management Journal, 37, 1177-1195.

Hambrick, D. C. and Mason, P. A. (1984). 'Upper echelons: the organization as a reflection of its top managers'. Academy of Management Review 9, 193-206.

Hülsheger, U., Anderson, N. R. \& Salgado, J.F. (2009). 'Team-Level Predictors of Innovation at Work: A Comprehensive Meta-Analysis Spanning Three Decades of Research'. Journal of Applied Psychology 94, 1128.

Ilgen, D. (2005). 'Teams in Organizations: From Input-Process-Output Models to Imoi Models'. Annual Review of Psychology 56, 517-43. 
Jansen, J., van den Bosch, F. and Volberda H. (2005). 'Managing Potential and Realized Absorptive Capacity: How Do Organizational Antecedents Matter?' Academy of Management Journal, 48, 999-1015.

Kogut, B. \& Zander, U. (1993). 'Knowledge of the firm and the evolutionary theory of the multinational corporation'. Journal of International Business Studies, 34, 516-529.

Laursen, K. and Salter, A.J. (2006). 'Open for innovation: the role of openness in explaining innovation performance among UK manufacturing firms'. Strategic Management Journal, 27,131-150.

Laursen, K. (2012). 'Keep Searching and You'll Find: What Do We Know about Variety Creation through Firms' Search Activities for Innovation?'. Industrial and Corporate Change 21, 1181-1220.

Maggitti, P., Smith, K.G. and Katila, R. (2013). 'The Complex Search Process of Invention'. Research Policy, 42, 90-100.

Ocasio, W. (1997). 'Towards an attention-based view of the firm'. Strategic Management Journal, 18, 187-206.

O’Reilly, C. A., Chatman, J., \& Caldwell, D. F. (1991). 'People and organizational culture: A profile comparison approach to assessing person-organization fit'. Academy of Management Journal 34, 487-516.

Paruchuri S, Awate S. (2017). 'Organizational Knowledge Networks and Local Search: The Role of Intra-Organizational Inventor Networks'. Strategic Management Journal 38, $657-675$.

Podsakoff, P. M., MacKenzie, S. B., Lee, J.-Y. and Podsakoff, N. P. (2003). 'Common method biases in behavioral research: A critical review of the literature and recommended remedies'. Journal of Applied Psychology 88, 879-903. 
Podsakoff, P. M., MacKenzie, S. B. and Podsakoff, N. P. (2012). 'Sources of method bias in social science research and recommendations on how to control it'. Annual Review of Psychology 63, 539-569.

Puranam P, Raveendran M, Knudsen T. (2012). 'Organization Design: The Epistemic Interdependence Perspective'. Academy of Management Review 37, 419-440.

Reilly, M. and Scott, P.S. (2014). 'Subsidiary Driven Innovation within Shifting MNC Structures: Identifying New Challenges and Research Directions'. Technovation 34, 190202.

Salter, A., Ter Wal, A., Criscuolo, P. and Alexy, O. (2015). 'Open for Ideation: IndividualLevel Openness and Idea Generation in R\&D'. Journal of Product Innovation Management, 32, 488-504.

Song, X.M., Montoya-Weiss, M. \& Schmidt, J.B. (1997). ,Antecedents and Consequences of Cross-Functional Cooperation: A Comparison of R\&D, Manufacturing, and Marketing Perspectives'. Journal of Product Innovation Management 14, 35-47.

Srivastava, A., Bartol, K. M. \& E. A. Locke (2006). 'Empowering leadership in management teams: Effects on knowledge sharing, efficacy and performance'. Academy of Management Journal 49, 1239-1251.

Thompson, J.D. (1967). Organizations in Action: Social Science Bases of Administrative Theory. New York, McGraw-Hill.

Tortoriello, M. (2015). 'The Social Underpinnings of Absorptive Capacity: The Moderating Effects of Structural Holes on Innovation Generation Based on External Knowledge'. Strategic Management Journal, 36, 586-597.

Tsai, W. (2001). 'Knowledge Transfer in Intraorganizational Networks: Effects of Network Position and Absorptive Capacity on Business Unit Innovation and Performance'. Academy of Management Journal, 44, 996-1004. 
Tsai, W. and Ghoshal, S. (1998). 'Social Capital and Value Creation: The Role of Intrafirm Networks'. Academy of Management Journal, 41, 464-476.

West, M. (2002). 'Sparkling Fountains or Stagnant Ponds: An Integrative Model of Creativity and Innovation Implementation in Work Groups'. Applied Psychology 51, 355-387.

West, M., \& Anderson, N. (1996). 'Innovation in Top Management Teams'. Journal of Applied Psychology 81, 680. 
Table 1: Overview of recent empirical papers on employee-level innovation

\begin{tabular}{|c|c|c|c|c|c|}
\hline & Unit of analysis & $\begin{array}{l}\text { Relevant knowledge } \\
\text { for innovation }\end{array}$ & Data \& sample & Dependent variable & Main explanatory factor \\
\hline \multicolumn{6}{|l|}{$\begin{array}{c}\text { External } \\
\text { innovation search }\end{array}$} \\
\hline Gruber et al. (2013) & Scientists & $\begin{array}{l}\text { External and intra- } \\
\text { organizational }\end{array}$ & 1880 inventors & $\begin{array}{l}\text { Inventors' technological } \\
\text { recombination breadth }\end{array}$ & $\begin{array}{l}\text { Educational background } \\
\text { of inventors }\end{array}$ \\
\hline Criscuolo et al. (2014) & Scientists within a firm & $\begin{array}{l}\text { Focus on individual } \\
\text { innovative activities }\end{array}$ & One MNE & Innovation performance & Bootlegging \\
\hline Salter et al. (2015) & Scientists within a firm & External & One MNE & Ideation performance & Openness \\
\hline Dahlander et al. (2016) & Scientists within a firm & $\begin{array}{l}\text { External and intra- } \\
\text { organizational }\end{array}$ & One MNE & Innovation output (patents) & $\begin{array}{l}\text { External search breadth; } \\
\text { attention to information }\end{array}$ \\
\hline Bogers et al. (2017) & All employees & External & 480 firms & External knowledge sourcing & Educational diversity \\
\hline \multicolumn{6}{|l|}{$\begin{array}{l}\text { Intra-organizational networks } \\
\text { and innovation }\end{array}$} \\
\hline Guler \& Nerkar (2012) & Scientists within a firm & Intra-organizational & 33 pharmaceutical firms & Firm's innovation & Local and global cohesion \\
\hline Carnabuci \& Operti (2013) & Scientists within a firm & Intra-organizational & 126 semiconductor firms & $\begin{array}{l}\text { Firm's recombinant reuse } \\
\text { and creation }\end{array}$ & $\begin{array}{l}\text { Collaborative integration and } \\
\text { knowledge diversity }\end{array}$ \\
\hline Grigoriou \& Rothaermel (2014) & Scientists within a firm & Intra-organizational & 106 pharmaceutical firms & Firm's innovation & Relational stars \\
\hline Tortoriello (2015) & Scientists within a firm & $\begin{array}{l}\text { External and intra- } \\
\text { organizational }\end{array}$ & One MNE & Scientists' innovation & Inventors' network position \\
\hline Paruchuri \& Awate (2017) & Scientists within a firm & Intra-organizational & Four semiconductor firms & $\begin{array}{l}\text { Depth and breadth } \\
\text { of local search }\end{array}$ & $\begin{array}{l}\text { Inventors' reach and span } \\
\text { of structural holes }\end{array}$ \\
\hline
\end{tabular}


Figure 1: A multilevel model of innovation intensity in a multi-unit company's functional Departments.

BU-specific conditions: structure and strategy; market conditions; national regulations

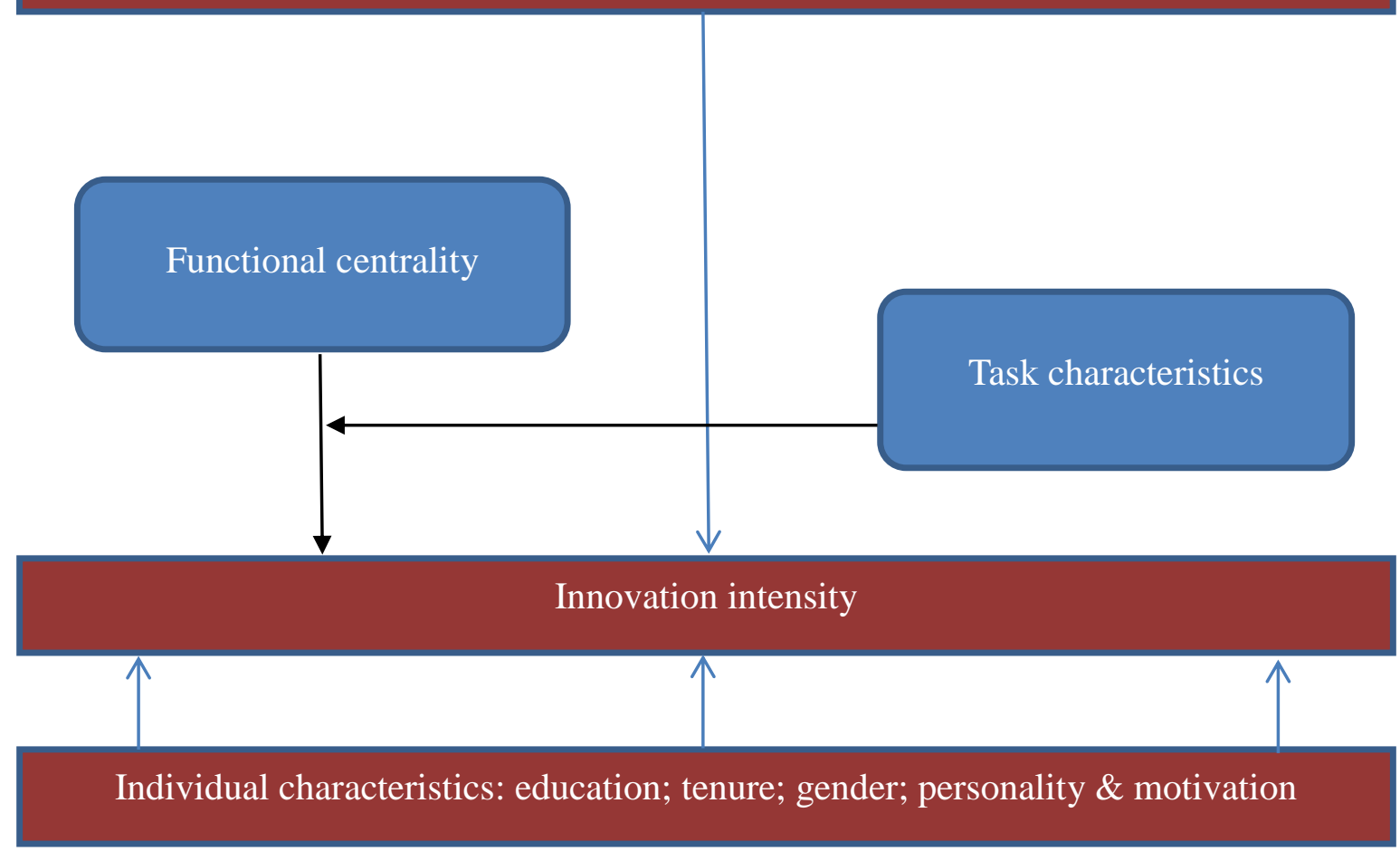


Table 2a: Survey respondents, by BUs

\begin{tabular}{|ccc|}
\hline Business unit & Survey responses & Response rate \\
Digi / Malaysia & 1735 & $79 \%$ \\
Dtac / Thailand & 3398 & $74 \%$ \\
Serbia & 959 & $72 \%$ \\
Norway & 2755 & $66 \%$ \\
Montenegro & 196 & $61 \%$ \\
Hungary & 593 & $59 \%$ \\
Pakistan & 1081 & $56 \%$ \\
Grameenphone / & 1653 & $55 \%$ \\
Bangladesh & 868 & $54 \%$ \\
Sweden & 281 & $51 \%$ \\
Telenor ASA / central unit & 932 & $48 \%$ \\
Denmark & 179 & $43 \%$ \\
Digital / central unit & 294 & $37 \%$ \\
Broadcast / central unit & & $\mathbf{6 3} \%$ \\
Sum & $\mathbf{1 5 7 9 3}$ & \\
\hline
\end{tabular}


Table 2b: Survey respondents, by FDs

\begin{tabular}{|ccc|}
\hline Functional Departments & Survey responses & $\begin{array}{c}\text { Share of total } \\
\text { survey responses }\end{array}$ \\
Marketing \& sales & 5744 & $37 \%$ \\
Technology and networks & 3420 & $22 \%$ \\
Sourcing & 290 & $2 \%$ \\
Operations & 3521 & $23 \%$ \\
R \& D & 282 & $2 \%$ \\
Strategy & 210 & $1 \%$ \\
Support functions & 1857 & $12 \%$ \\
Top management & 102 & $1 \%$ \\
Sum & $\mathbf{1 5 4 2 6}$ & $\mathbf{1 0 0 \%}$ \\
\hline
\end{tabular}


Figure 2: Employees' innovation intensity: distribution

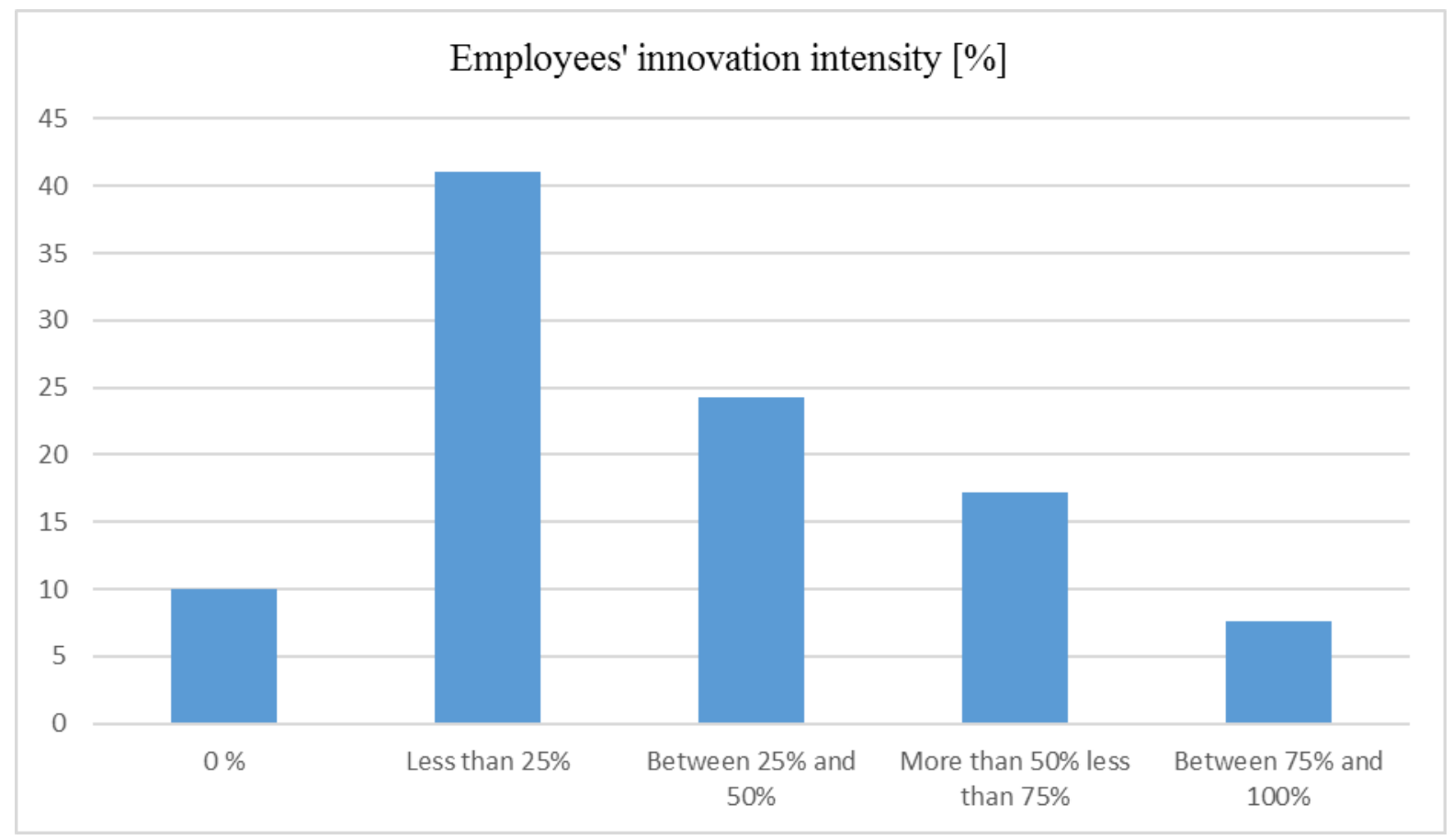


Table 3a: Employees' innovation intensity: distribution across FDs.

\begin{tabular}{|cccccc|}
\hline & $\mathbf{0 \%}$ & $\begin{array}{c}\text { Less than } \\
\mathbf{2 5 \%}\end{array}$ & $\begin{array}{c}\text { Between 25\% } \\
\text { and 50\% }\end{array}$ & $\begin{array}{c}\text { Between 50\% } \\
\text { and 75\% }\end{array}$ & $\begin{array}{c}\text { Between 75\% } \\
\text { and 100\% }\end{array}$ \\
Marketing \& sales & 13.53 & 42.68 & 22.39 & 14.19 & 7.21 \\
Technology & 10.75 & 45.81 & 23.58 & 14.51 & 5.35 \\
Sourcing & 6.17 & 60.49 & 22.22 & 8.02 & 3.09 \\
Operations & 6.83 & 28.02 & 25.59 & 26.53 & 13.02 \\
R\&D & 5.88 & 38.97 & 24.26 & 19.12 & 3.76 \\
Strategy & 4.65 & 48.06 & 30.23 & 13.18 & 3.24 \\
Support functions & 7.07 & 48.77 & 27.09 & 13.84 & 0.00 \\
Top management & 10.53 & 47.37 & 28.95 & 13.16 & \\
\hline
\end{tabular}

Table 3b: Employees' innovation intensity: distribution across BUs.

\begin{tabular}{|c|c|c|c|c|c|}
\hline & $0 \%$ & $\begin{array}{l}\text { Less than } \\
25 \%\end{array}$ & $\begin{array}{c}\text { Between } 25 \% \\
\text { and } 50 \%\end{array}$ & $\begin{array}{c}\text { Between } 50 \% \\
\text { and } 75 \%\end{array}$ & $\begin{array}{c}\text { Between } 75 \% \\
\text { and } 100 \%\end{array}$ \\
\hline ASA & 9.09 & 59.89 & 16.58 & 9.63 & 4.81 \\
\hline Broadcast & 9.8 & 62.25 & 18.63 & 6.37 & 2.94 \\
\hline DTAC & 1.36 & 19.03 & 30.14 & 33.94 & 15.52 \\
\hline Denmark & 17.58 & 56.77 & 14.96 & 6.89 & 3.8 \\
\hline DiGi & 5.32 & 31.52 & 31.77 & 21.63 & 9.77 \\
\hline Digital & 10 & 66 & 12 & 10 & 2 \\
\hline Grameenphone & 7.49 & 51.66 & 24.86 & 10.63 & 5.36 \\
\hline Hungary & 14.24 & 61.81 & 14.93 & 6.25 & 2.78 \\
\hline Montenegro & 8.91 & 59.41 & 20.79 & 7.92 & 2.97 \\
\hline Norge & 26.35 & 50.41 & 14.7 & 6.49 & 2.04 \\
\hline Pakistan & 6.52 & 48.54 & 28.99 & 11.37 & 4.58 \\
\hline Serbia & 9.78 & 55.98 & 25.82 & 7.34 & 1.09 \\
\hline
\end{tabular}


Table 4: Descriptive statistics for the main explanatory variables

\begin{tabular}{|cccccc|}
\hline Variable & Obs & Mean & Std. Dev. & Min & Max \\
CENTRAL_FD & 15426 & 4.389315 & 0.521557 & 2.857143 & 6.371428 \\
CENTRAL_BU & 15426 & 3.242633 & 0.64666 & 1.888889 & 6.25 \\
ANALYTICAL & 15426 & 5.222093 & 1.359834 & 1 & 7 \\
ENTREPRENEURIAL & 15426 & 4.860344 & 1.204336 & 1 & 7 \\
EFFICIENCY & 15426 & 5.179389 & 1.292652 & 1 & 7 \\
RESULT & 15426 & 5.649148 & 1.035141 & 1 & 7 \\
EMPOWERMENT & 15426 & 5.127382 & 1.504412 & 1 & 5 \\
DIVERSITY & 15426 & 5.476339 & 1.476732 & 1 & 5 \\
TENURE & 15417 & 3.101057 & 1.316598 & 1 & 4 \\
EDUCATION & 15426 & 2.885648 & 1.085047 & 0 & 1 \\
GENDER & 15426 & 3.565215 & 0.632091 & -5.6087 & 5.804348 \\
ATTITUDE & 15426 & 0.490667 & 0.796021 & & 5 \\
\hline
\end{tabular}


Table 5: Regression results: Baseline model specification

\begin{tabular}{|c|c|c|c|c|c|c|c|c|}
\hline & $\begin{array}{c}\text { Ordered } \\
\text { probit }\end{array}$ & $\begin{array}{c}\text { Hierarchical } \\
\text { ordered } \\
\text { probit }\end{array}$ & $\begin{array}{c}\text { Ordered } \\
\text { probit }\end{array}$ & $\begin{array}{c}\text { Hierarchical } \\
\text { ordered } \\
\text { probit }\end{array}$ & $\begin{array}{c}\text { Ordered } \\
\text { probit }\end{array}$ & $\begin{array}{c}\text { Hierarchical } \\
\text { ordered } \\
\text { probit }\end{array}$ & $\begin{array}{c}\text { Ordered } \\
\text { probit }\end{array}$ & $\begin{array}{c}\text { Hierarchical } \\
\text { ordered } \\
\text { probit }\end{array}$ \\
\hline DIVERSITY & $\begin{array}{c}0,004 \\
(0,0089)\end{array}$ & $\begin{array}{c}0,0016 \\
(0,0090)\end{array}$ & $\begin{array}{c}-0,043 * * * \\
(0,011)\end{array}$ & $\begin{array}{c}-0,044 * * * \\
(0,011)\end{array}$ & $\begin{array}{c}-0,042 * * * \\
(0,011)\end{array}$ & $\begin{array}{c}-0,044 * * * \\
(0,011)\end{array}$ & $\begin{array}{c}-0,043 * * * \\
(0,011)\end{array}$ & $\begin{array}{c}-0,044 * * * \\
(0,011)\end{array}$ \\
\hline TENURE & $\begin{array}{c}0,014 \\
(0,0096)\end{array}$ & $\begin{array}{c}0,010 \\
(0,0096)\end{array}$ & $\begin{array}{c}0,013 \\
(0,0096)\end{array}$ & $\begin{array}{c}0,009 \\
(0,0097)\end{array}$ & $\begin{array}{c}0,012 \\
(0,0096)\end{array}$ & $\begin{array}{c}0,010 \\
(0,0097)\end{array}$ & $\begin{array}{c}0,013 \\
(0,0096)\end{array}$ & $\begin{array}{c}0,010 \\
(0,0097)\end{array}$ \\
\hline EDUCATION & $\begin{array}{c}0,038 * * \\
(0,014)\end{array}$ & $\begin{array}{l}0,024 * \\
(0,014)\end{array}$ & $\begin{array}{c}0,036 * * \\
(0,014)\end{array}$ & $\begin{array}{l}0,025 * \\
(0,014)\end{array}$ & $\begin{array}{c}0,031 * * \\
(0,014)\end{array}$ & $\begin{array}{l}0,024 * \\
(0,014)\end{array}$ & $\begin{array}{c}0,032 * * \\
(0,014)\end{array}$ & $\begin{array}{l}0,025 * \\
(0,014)\end{array}$ \\
\hline GENDER & $\begin{array}{c}0,033 \\
(0,023)\end{array}$ & $\begin{array}{l}0,042 * \\
(0,023)\end{array}$ & $\begin{array}{c}0,035 \\
(0,023)\end{array}$ & $\begin{array}{l}0,042 * \\
(0,023)\end{array}$ & $\begin{array}{l}0,044 * \\
(0,023)\end{array}$ & $\begin{array}{l}0,042 * \\
(0,023)\end{array}$ & $\begin{array}{l}0,039 * \\
(0,023)\end{array}$ & $\begin{array}{l}0,042 * \\
(0,023)\end{array}$ \\
\hline ATTITUDE & $\begin{array}{c}-0,161 * * * \\
(0,017)\end{array}$ & $\begin{array}{c}-0,156 * * * \\
(0,017)\end{array}$ & $\begin{array}{c}-0,074 * * * \\
(0,019)\end{array}$ & $\begin{array}{c}-0,074 * * * \\
(0,019)\end{array}$ & $\begin{array}{c}-0,076 * * * \\
(0,019)\end{array}$ & $\begin{array}{c}-0,075 * * * \\
(0,019)\end{array}$ & $\begin{array}{c}-0,075 * * * \\
(0,019)\end{array}$ & $\begin{array}{c}-0,074 * * * \\
(0,019)\end{array}$ \\
\hline ANALYTICAL & & & $\begin{array}{c}0,031 * * \\
(0,013)\end{array}$ & $\begin{array}{c}0,026^{* *} \\
(0,013)\end{array}$ & $\begin{array}{c}0,028 * * \\
(0,013)\end{array}$ & $\begin{array}{c}0,027 * * \\
(0,013)\end{array}$ & $\begin{array}{c}0,029 * * \\
(0,013)\end{array}$ & $\begin{array}{c}0,026 * * \\
(0,013)\end{array}$ \\
\hline ENTREPRENEURIAL & & & $\begin{array}{c}0,150 * * * \\
(0,016)\end{array}$ & $\begin{array}{c}0,147 * * * \\
(0,016)\end{array}$ & $\begin{array}{c}0,144 * * * \\
(0,016)\end{array}$ & $\begin{array}{c}0,146 * * * \\
(0,016)\end{array}$ & $\begin{array}{c}0,146^{* * * *} \\
(0,016)\end{array}$ & $\begin{array}{c}0,147 * * * \\
(0,016)\end{array}$ \\
\hline RESULT & & & $\begin{array}{c}-0,141 * * * \\
(0,019)\end{array}$ & $\begin{array}{c}-0,128 * * * \\
(0,019)\end{array}$ & $\begin{array}{c}-0,136 * * * \\
(0,019)\end{array}$ & $\begin{array}{c}-0,129 * * * \\
(0,019)\end{array}$ & $\begin{array}{c}-0,136 * * * \\
(0,019)\end{array}$ & $\begin{array}{c}-0,128 * * * \\
(0,019)\end{array}$ \\
\hline EFFICIENCY & & & $\begin{array}{c}0,069 * * * \\
(0,012)\end{array}$ & $\begin{array}{c}0,067 * * * \\
(0,012)\end{array}$ & $\begin{array}{c}0,067 * * * \\
(0,012)\end{array}$ & $\begin{array}{c}0,066^{* * *} * \\
(0,012)\end{array}$ & $\begin{array}{c}0,068 * * * \\
(0,012)\end{array}$ & $\begin{array}{c}0,066 * * * \\
(0,012)\end{array}$ \\
\hline EMPOWERMENT & & & $\begin{array}{c}0,035 * * * \\
(0,011)\end{array}$ & $\begin{array}{c}0,030 * * * \\
(0,011)\end{array}$ & $\begin{array}{c}0,032 * * * \\
(0,011)\end{array}$ & $\begin{array}{c}0,030 * * * \\
(0,011)\end{array}$ & $\begin{array}{c}0,033 * * * \\
(0,011)\end{array}$ & $\begin{array}{c}0,030 * * * \\
(0,011)\end{array}$ \\
\hline CENTRAL_FD & & & & & $\begin{array}{c}0,394 * * * \\
(0,051)\end{array}$ & $\begin{array}{c}0,190 * * * \\
(0,072)\end{array}$ & & \\
\hline CENTRAL_BU & & & & & & & $\begin{array}{c}0,281 * * * \\
(0,045)\end{array}$ & $\begin{array}{c}0,091 \\
(0,065)\end{array}$ \\
\hline Pseudo R-squared & 0,098 & & 0,107 & & 0,110 & & 0,109 & \\
\hline Observations & 8225 & 8225 & 8225 & 8225 & 8225 & 8225 & 8225 & 8225 \\
\hline
\end{tabular}

Significance levels: $* \mathrm{p}<.05 ; * * \mathrm{p}<.01 ; * * * \mathrm{p}<.001$ 
Table 6: Hierarchical (mixed) model: Estimated random effects coefficients for each functional department

\begin{tabular}{|ccccccccccc}
\hline & Mark/sale & Technology & Sourcing & Operations & R\&D & Strategy & Support & Top manag. \\
CENTRAL_FD & 0,0038848 & $-0.0125681^{* * *}$ & $-0.0324469^{* * *}$ & $0.1313327 * * *$ & $0.1122032^{* * * *}$ & $-0.0221141^{* * *}$ & $0.0416994^{* * *}$ & $-0.0190825^{*}$ \\
CENTRAL_BU & 0,0016767 & $-0.0056875^{* * *}$ & $-0.0293485^{* * *}$ & $0.0859473^{* * *}$ & $0.0750335^{* * * *}$ & $-0.0210098^{* * *}$ & $0.0256698^{* * *}$ & $-0.0122593^{*}$ \\
& & & & & & & & \\
\hline
\end{tabular}

Random effect slopes for the different explanatory variables across functional Departments. Higher values indicate greater deviation from the mean across all functions. $* \mathrm{p}<.05 ; * * \mathrm{p}<.01 ; * * * \mathrm{p}<.001$ 
Table 7: Regression results: Test of hypothesis 1 (inverted U-shape relationship)

\begin{tabular}{|c|c|c|c|c|}
\hline & $\begin{array}{c}\text { Ordered } \\
\text { probit }\end{array}$ & $\begin{array}{c}\text { Hierarchical } \\
\text { ordered } \\
\text { probit }\end{array}$ & $\begin{array}{c}\text { Ordered } \\
\text { probit }\end{array}$ & $\begin{array}{l}\text { Hierarchica } \\
\text { ordered } \\
\text { probit }\end{array}$ \\
\hline DIVERSITY & $\begin{array}{c}-0,042 * * * \\
(0,011)\end{array}$ & $\begin{array}{c}-0,044 * * * \\
(0,011)\end{array}$ & $\begin{array}{c}-0,043 * * * * \\
(0,011)\end{array}$ & $\begin{array}{c}-0,043 * * * \\
(0,011)\end{array}$ \\
\hline TENURE & $\begin{array}{c}0,122 \\
(0,0096)\end{array}$ & $\begin{array}{c}0,010 \\
(0,0096)\end{array}$ & $\begin{array}{c}0,012 \\
(0,0096)\end{array}$ & $\begin{array}{c}0,010 \\
(0,0097)\end{array}$ \\
\hline EDUCATION & $\begin{array}{c}0,030 * * \\
(0,014)\end{array}$ & $\begin{array}{l}0,024^{*} \\
(0,014)\end{array}$ & $\begin{array}{c}0,030 * * \\
(0,014)\end{array}$ & $\begin{array}{l}0,024^{*} \\
(0,014)\end{array}$ \\
\hline GENDER & $\begin{array}{l}0,044^{*} \\
(0,023)\end{array}$ & $\begin{array}{l}0,042^{*} \\
(0,023)\end{array}$ & $\begin{array}{c}0,037 \\
(0,023)\end{array}$ & $\begin{array}{l}0,041^{*} \\
(0,023)\end{array}$ \\
\hline ATTITUDE & $\begin{array}{c}-0,076^{* * * *} \\
(0,019)\end{array}$ & $\begin{array}{c}-0,075^{* * *} * \\
(0,019)\end{array}$ & $\begin{array}{c}-0,074 * * * * \\
(0,019)\end{array}$ & $\begin{array}{c}-0,074 * * * \\
(0,019)\end{array}$ \\
\hline ANALYTICAL & $\begin{array}{c}0,028 * * \\
(0,013)\end{array}$ & $\begin{array}{c}0,026^{* *} \\
(0,013)\end{array}$ & $\begin{array}{c}0,028 * * \\
(0,013)\end{array}$ & $\begin{array}{c}0,026^{* *} \\
(0,013)\end{array}$ \\
\hline ENTREPRENEURIAL & $\begin{array}{c}0,144 * * * \\
(0,016)\end{array}$ & $\begin{array}{c}0,146^{* * * *} \\
(0,016)\end{array}$ & $\begin{array}{c}0,146 * * * \\
(0,016)\end{array}$ & $\begin{array}{c}0,147 * * * \\
(0,016)\end{array}$ \\
\hline RESULT & $\begin{array}{c}-0,136^{* * * *} \\
(0,019)\end{array}$ & $\begin{array}{c}-0,129 * * * \\
(0,019)\end{array}$ & $\begin{array}{c}-0,135 * * \\
(0,019)\end{array}$ & $\begin{array}{c}-0,129 * * * \\
(0,019)\end{array}$ \\
\hline EFFICIENCY & $\begin{array}{c}0,067 * * * \\
(0,012)\end{array}$ & $\begin{array}{c}0,066^{* * * *} \\
(0,012)\end{array}$ & $\begin{array}{c}0,068 * * * \\
(0,012)\end{array}$ & $\begin{array}{c}0,066 * * * \\
(0,012)\end{array}$ \\
\hline EMPOWERMENT & $\begin{array}{c}0,032 * * * \\
(0,011)\end{array}$ & $\begin{array}{c}0,030 * * * \\
(0,011)\end{array}$ & $\begin{array}{c}0,033 * * * \\
(0,011)\end{array}$ & $\begin{array}{c}0,030 * * * \\
(0,011)\end{array}$ \\
\hline $\begin{array}{c}\text { CENTRAL_FD } \\
(\text { CENTRAL_FD })^{2}\end{array}$ & $\begin{array}{l}1,289 * * \\
(0,548) \\
-0,101 \\
(0,061)\end{array}$ & $\begin{array}{c}0,296 \\
(0,661) \\
-0,011 \\
(0,072)\end{array}$ & & \\
\hline $\begin{array}{c}\text { CENTRAL_BU } \\
(\text { CENTRAL_BU })^{2}\end{array}$ & & & $\begin{array}{c}1,233 * * * \\
(0,287) \\
-0,130 * * * \\
(0,039)\end{array}$ & $\begin{array}{l}0,609 * \\
(0,331) \\
-0,069 \\
(0,044)\end{array}$ \\
\hline $\begin{array}{c}\text { Turning point } \\
\text { of quadratic relationship }\end{array}$ & 6,4 & 13,2 & 4,7 & 4,4 \\
\hline $\begin{array}{l}\text { Turning point's position vis-à-vis } \\
\text { range of organizational centrality }\end{array}$ & Outside & Outside & Inside & Inside \\
\hline Pseudo R-squared & 0,110 & & 0,109 & \\
\hline Observations & 8225 & 8225 & 8225 & 8225 \\
\hline
\end{tabular}

Significance levels: $* \mathrm{p}<.05 ; * * \mathrm{p}<.01 ; * * * \mathrm{p}<.001$ 
Table 8: Test of hypothesis 2 (moderating effects of task characteristics on linear relationship). Marginal effects of interaction variables.

\begin{tabular}{|c|c|c|c|}
\hline Interaction variables & Ordered probit & $\begin{array}{c}\text { Hierarchical } \\
\text { ordered probit }\end{array}$ & $\begin{array}{c}\text { Test of } \\
\text { Hypothesis }\end{array}$ \\
\hline CENTRAL_FD $\cdot$ ANALYTICAL & $+0,062 * *$ & $+0,021^{*}$ & $\mathrm{H} 2 \mathrm{a}$ \\
\hline CENTRAL_BU $\bullet$ ANALYTICAL & $+0,036^{* * *}$ & $+0,008 * * *$ & $\mathrm{H} 2 \mathrm{a}$ \\
\hline CENTRAL_FD • ENTREPRENEURIAL & $+0,033 * * *$ & $+0,008$ & $\mathrm{H} 2 \mathrm{~b}$ \\
\hline CENTRAL_BU • ENTREPRENEURIAL & $+0,077 * *$ & $+0,024 *$ & $\mathrm{H} 2 \mathrm{~b}$ \\
\hline CENTRAL_FD $\cdot$ RESULT & $-0,020 * * *$ & $-0,010^{* *}$ & $\mathrm{H} 2 \mathrm{c}$ \\
\hline CENTRAL_BU $\bullet$ RESULT & $-0,029 * * *$ & $-0,012 * *$ & $\mathrm{H} 2 \mathrm{c}$ \\
\hline
\end{tabular}

Significance levels: $* \mathrm{p}<.05 ; * * \mathrm{p}<.01 ; * * * \mathrm{p}<.001$ 
Table 9: Test of hypothesis 2 (moderating effects of task characteristics on quadratic relationship).

\begin{tabular}{|c|c|c|c|c|}
\hline Interaction variables & & Ordered probit & $\begin{array}{c}\text { Hierarchical } \\
\text { ordered probit }\end{array}$ & $\begin{array}{c}\text { Test of } \\
\text { Hypothesis }\end{array}$ \\
\hline$(\text { CENTRAL_BU })^{2} \cdot$ ANALYTICAL & $\begin{array}{l}\text { Flattening or steepening: } \\
\text { Shift in turning point: }\end{array}$ & $\begin{array}{l}-0,019 \\
-0,22 *\end{array}$ & $\begin{array}{l}-0,012 \\
-0,23\end{array}$ & $\mathrm{H} 2 \mathrm{a}$ \\
\hline$(\text { CENTRAL_BU })^{2} \cdot$ ENTREPRENEURIAL & $\begin{array}{l}\text { Flattening or steepening: } \\
\text { Shift in turning point: }\end{array}$ & $\begin{array}{c}-0,028 \\
-0,18\end{array}$ & $\begin{array}{l}-0,020 \\
-0,17\end{array}$ & $\mathrm{H} 2 \mathrm{~b}$ \\
\hline$\left(\mathrm{CENTRAL} \_\mathrm{BU}\right)^{2} \cdot \mathrm{RESULT}$ & $\begin{array}{l}\text { Flattening or steepening: } \\
\text { Shift in turning point: }\end{array}$ & $\begin{array}{l}-0,035 \\
-0,29 *\end{array}$ & $\begin{array}{c}-0,019 \\
-0,29\end{array}$ & $\mathrm{H} 2 \mathrm{c}$ \\
\hline
\end{tabular}

Significance levels: $* \mathrm{p}<.05 ; * * \mathrm{p}<.01 ; * * * \mathrm{p}<.001$ 